\title{
Evaporative Coolers Air Conditioners Devices as a Source of Legionella Pneumophila in Khartoum State, Sudan and Recommended Measures of Control
}

\author{
Reem Mohamed Elfatih Ali Elsanousi \\ Department of Microbiology, College of Medicine, University of Bahri, Khartoum, Sudan \\ Email address: \\ sanousireem@gmail.com \\ To cite this article: \\ Reem Mohamed Elfatih Ali Elsanousi Elsanousi. Evaporative Coolers Air Conditioners Devices as a Source of Legionella Pneumophila in \\ Khartoum State, Sudan and Recommended Measures of Control. International Journal of Microbiology and Biotechnology. \\ Vol. 5, No. 3, 2020, pp. 93-96. doi: 10.11648/j.ijmb.20200503.13
}

Received: May 8, 2020; Accepted: May 29, 2020; Published: June 9, 2020

\begin{abstract}
This study was designed to substantiate the role of the evaporative coolers air conditioners in the proliferation of the genus Legionella. In addition to sort out, isolate and identify the genus Legionella including Legionella pneumophila, the causative agent of Legionnaires' disease and Pontiac fever from a new source. This type of air conditioners depends on water in their operation. They cool the air by filtering it through evaporation of water which is widely used in the Sudan. The evaporative air conditioning units considered as reservoirs of the ubiquitous bacteria which it harbored by amoeba. Legionella species can proliferate in amoeba and in biofilms that promote the growth of the bacteria even in the bad conditions. The study was done in Khartoum State including different premises from which water samples of evaporative coolers air conditioners were collected. Five hundred and fifty five water samples were collected, treated, cultured, identified and confirmed by gold standard culture technique using Buffered Charcoal Yeast Extract Agar (BCYE - $\alpha$ medium), Glycine Vancomycin PolymxinCycloheximide Agar (G V P C Medium) and biochemical techniques well as Real Time PCR test. The results of Legionella species obtained from this study were $42.3 \%$ of the total collected samples with a rate of $11 \%$ for Legionella pneumophila. Recommended measures of control must be applied including this type of air conditioners to prevent Legionella out breaks.
\end{abstract}

Keywords: Evaporative Coolers Air Conditioners Devices, Legionella pneumophila, Control Measures

\section{Introduction}

Evaporative cooler conditioners operation is by the theory of evaporation. The evaporation depends on the transition of liquid water to water vapor. This can cool the air using much less energy than refrigeration [8]. Since the 1976 outbreak in Philadelphia, which led to the detection and description of the bacteria Legionella pneumophila, many outbreaks followed and were reported and they frequently involved hospitals. Infections were traced to the colonization parts of air - conditioning plants [1, 5, 21, 24]. But most outbreaks and recurrent single cases in hospitals were associated with contaminated potable water and hot-water systems [13]. Legionella pneumophila is the causative agent of Legionnaires' disease which can infect specific species of amoebae like Acanthamoeba polyphaga and Acanthamoeba castellanii in aquatic environments and can multiply as an intracellular parasite in human phagocytic cells [2]. Legionella are ubiquitous bacteria found in different types of water sources in the environment. Their growth is especially favored in human made warm water systems, including cooling towers, hot tubes, showers and swimming pools [19]. Legionella species are able to survive in moist environments for long times and grow well at temperature ranging between $20^{\circ} \mathrm{C}-42^{\circ} \mathrm{C}$ [6]. Legionella pneumophila serogroup 1 was reported to be responsible for up to eighty percent $(80 \%)$ of Legionnaires'disease reported cases [11]. Legionella longbeachae and other species were identified as the cause of several infections [22]. A previous study in England by Kirby et al. [16] showed that the total cases of mortality associated with Legionella pneumonia was $19 \%$, but it can be as high as $80 \%$ among immunocompromised patients and an early initiation of appropriate therapy will improve better treatment. Temperature is a crucial factor in the colonization 
and proliferation of Legionella species in the environment and water systems. Therefore, adjustment and maintenance of the temperature of hot- and cold- water systems within the range below $20^{\circ} \mathrm{C}$ for the cold water and above $60^{\circ} \mathrm{C}$ for the hot water to prevent or minimize the growth of Legionella species is an important control measure to avoid the risk of Legionella infection [9]. Legionella species are difficult to control in environmental sources due to their resistance to disinfectants, association with biofilms and parasitism of protozoan hosts $[15,20,23]$. Disinfection can help to control the multiplication of Legionella species in water and in air conditioning systems by applying more effective measures including the usage of filters, copper- silver ionization, and chlorine- dioxide or mono- chloramines [18]. Hospitals that care for immunocompromised patients should monitor potable water systems for the presence of Legionella species and treat water, if it is found [12]. Decontamination of colonized devices is important to interrupt outbreaks and prevent recurrence of sporadic cases. Two American studies in hospitals confirmed that the frequency with Legionella pneumophila isolated from patients with pneumonia was reduced from $16.3 \%$ to $0.1 \%$ over a 6 - year period and in immunocompromised patients from $76 \%$ to $0.8 \%$ over a 10 years period after applying control measures, including decontamination of the plumbing systems, monitoring of Legionella species in water, examination of all clinical cases and specimens for the genus Legionella, using sterile water for all medical applications $[10,14]$.

\section{Material and Methods}

Five hundred and twenty five evaporative coolers air conditioners water samples were collected from different premises including hospitals, universities, schools, offices and houses. Samples were transferred to the research laboratory for bacteriological examination which inoculated onto Buffered Charcoal Yeast Extract Agar (BCYE - $\alpha$ medium) and Glycine Vancomycin Polymxin Cycloheximide Medium (G V P C medium) (Oxoid Laboratories, London). They were subjected to Gram's stain and biochemical assay according to Barraow and Feltham [3]. Samples were confirmed using Real Time PCR technique (Sacace Biotechnologies, Italy). Samples temperature and $\mathrm{pH}$ were measured. All methods of bacterial isolation, identification and confirmation were prescribed by Elsanousi and Elsanousi
[7].

\section{Data Analysis}

The data were analyzed using SPSS 21 with reference Pvalue $\leq(0.05)$. The results were subjected to statistical analysis in the form of frequencies and percentages. The significance of these frequencies was tested using chi-square test.

\section{Results}

Temperature of all collected samples were ranged between $14^{\circ} \mathrm{C}-37^{\circ} \mathrm{C}$, during sampling and $\mathrm{pH}$ ranged between 6.7 8.6 for most of the samples. All positive samples showed growth on BCYE medium and GVPC medium. (Figure 1) Legionella isolates gave negative reaction to Gram's stain technique (figure 2) and positive reactions to: catalase, oxidase and gelatin hydrolysis tests. Legionella pneumophila was confirmed using Real Time PCR technique. Collected samples gave $42.3 \%$ positive results for Legionella species with a rate of $11 \%$ for Legionella pneumophila (table 1).

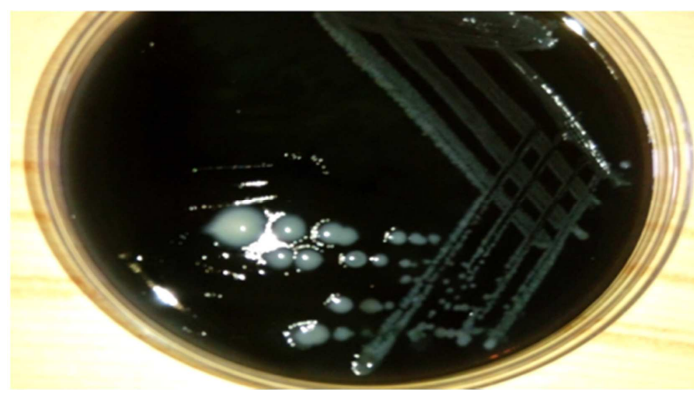

Figure 1. Colonies of Legionella pneumophila on CVPC medium

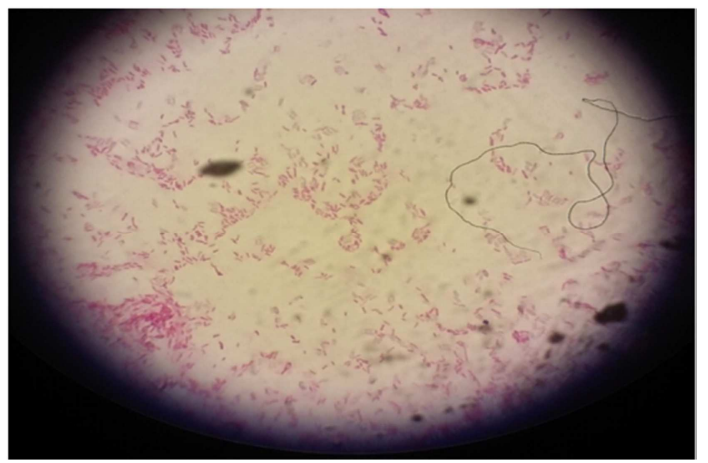

Figure 2. Gram's stain of Legionella pneumophila.

Table 1. The ratio of each category calculated from the total of positive and the total of negative samples (P-value of chi-square test=0.002 (Significant)

\begin{tabular}{|c|c|c|c|c|c|}
\hline \multirow{2}{*}{ Premises category } & \multirow{2}{*}{ Number of samples } & \multicolumn{2}{|c|}{ Positive samples (out of 222) } & \multicolumn{2}{|c|}{ Negative samples (out of 303) } \\
\hline & & Number & $\%$ & Number & $\%$ \\
\hline Hospitals & 105 & 58 & 26 & 47 & 15.5 \\
\hline Offices & 105 & 52 & 23.4 & 53 & 17.5 \\
\hline Schools & 105 & 41 & 18.5 & 64 & 21.1 \\
\hline Houses & 105 & 38 & 17.1 & 67 & 22.1 \\
\hline Universities & 105 & 33 & 15 & 72 & 23.8 \\
\hline Total & 525 & 222 & 42.3 & 303 & 57.7 \\
\hline
\end{tabular}




\section{Discussion}

Evaporative coolers air conditioners devices are an oldest forms of climate control still found today. They remain good alternatives to traditional air conditioners. They are very effective and efficient when used properly. Due to the evaporative process used by these swamp coolers, these cooling units are best used in hot, dry climates, which prevail worldwide. In the Sudan, it is the most prevalent type of air conditioners. Because of that it requires low energy and inexpensive costs of manufacturing. This study was focusing on the prevalence of Legionella pneumophila in evaporative coolers devices as reservoirs of the bacteria, because they depend on water in their operation which create wet, favorable environment for this ubiquities bacteria. There are other factors that can maintain the growth of the bacteria like suitable temperature that was found between $20^{\circ} \mathrm{C}$ and $37^{\circ} \mathrm{C}$ in most of our studied samples. Some studies showed that, the isolation of Legionella pneumophila was obtained on water at temperatures between $25^{\circ} \mathrm{C}$ and $45^{\circ} \mathrm{C}$ with an optimal temperature range of $32^{\circ} \mathrm{C}-42^{\circ} \mathrm{C}$. Also, the conditioners reservoirs contain sediments that can support bacterial growth, such as rust, sludge, protozoa and organic matters, which enhance the biofilm formation [25]. The study paid great attention to the status of the air conditioner whether new or old. We hypothesized that the old devices may contain a lot of organisms than the new devices, but we found that of no value. The most important matter was the cleanliness of their water storages and continuing in water renewal and periods of their operation. The instrument, which operates for long periods, should be looked after for its cleanliness and water renewal. This will give negative results for growth of Legionella most of the time. This is in contrast to others that were operated for fewer periods without cleaning and without water changing. The climate and weather play a big role in adjusting the external temperature which affects the bacterial prevalence and affect the conditioners performance. Khartoum State revealed a prevalence rate of $42.3 \%$ for Legionella species in the evaporative coolers conditioners which may cause a great risk, especially when we notice that the prevalence of Legionella pneumophila was $11 \%$. Evaporative coolers air conditioners devices under the study were supplemented with treated water, for this reason we referred to the above measures and we recommend to apply general measures of control like eradication of the microorganisms from water systems using disinfectants [4]. Also we recommend strongly for adding additional doses disinfectant like chlorine and chlorine derivatives to the water reservoirs of the evaporative coolers air conditioning units to avoid the multiplication of the bacteria and amoeba. The American center for disease control and prevention (CDC) recommend with the best practices based on the scientific information that is currently available to disinfect a hot tube contaminated with Legionella which it can be apply to disinfect water reservoirs of evaporative coolers air conditioners which modified as: Maintaining water temperatures outside the ideal range of
Legionella growth, ensuring adequate disinfection, maintaining devices to prevent corrosion and biofilm formation and regular monitoring for water management programs [17].

\section{Conclusion}

Evaporative coolers air conditioners units are remain highly sought after alternatives to traditional air conditioning devices especially in hot developing countries. This study was added and enrolled these devices as a source of Legionella pneumophila and other Legionella species. Measures of prevention and control must be applied to avoid Legionella outbreaks.

\section{References}

[1] Addiss, D. G., Davis, J. P., Laventure, M., Wand, P. J., Hutchinson, M. A. and McKinney, R. M (1989). Community acquired Legionnaires' disease associated with a cooling towers. Evidence for longer distance transport of Legionella pneumophila. Am. J. of Epidem, 130 (3). 557-568.

[2] Barker, J., and Brown, M. R. W (1994). "Trojan horses of the microbial world. Protozoa and the survival of bacterial pathogens in the environment." Microbiol 140 (6). 1253-1259.

[3] Barrow, G. I. and Feltham, R. K. A (2003). Cowan and Steel's Manual for the identification of the Medical Bacteria, $3^{\text {rd }}$ "edition. Cambridge University Press, Cambridge, U. K.

[4] Crespi, S. and Ferra, J (1997). Outbreak of legionellosis in a tourist complex in Lanzarote concomitant with a treatment of the water systems with mega doses of polyphosphates. Water Science and Technology, 35 (11-12). 307-309.

[5] Dondero, T. J. Rendtorff, R. C., Mallison, G. F., Weeks, R. M., Levy, J. S., Wong, E. W. and Schaffner, W (1980). An outbreak of Legionnaires' disease associated with a contaminated air-conditioning cooling tower. $N$ Eng. J. Med. 302 (7). 365-370.

[6] Edelstein, P. H., Murray, P. R., Baron, E. J., Jorgensen, J. H. and Landry, M. L (2007). Legionella. Manual of clinical microbiology $9^{\text {th }}$ Ed. 835-849.

[7] Elsanousi, R. M. A. and Elsanousi, S. M. (2017). Detection of Legionella pneumophila from evaporative coolers air conditioners in Khartoum State. Am. J. Microbiol. Res., 5 (6): 138-141.

[8] Essick, B (1945). Pad for evaporative coolers, filled Aug. 30, 1944, patented Dec1945. United state patent office, 2, 391, 558 Pad for evaporative coolers, Bryant Essick, Los Angeles, Calif. Application Augest 30, 1944, Serial No 551, 982.

[9] Green wood, D., Richard, C. B. and John, F (2002). Medical microbiology. Sixteen Edition, New York.

[10] Grosserode, M. Barbaree, J. M., Breiman, R. F and Dufour, A (1993). Continuous hyper chlorination for control of Nosocomial Legionella pneumophila pneumonia. a ten-year follow up of efficacy, environmental effects, and costs. In. Legionella. current status and emerging perspectives. Washington, DC, American Society for Microbiology. 226229. 
[11] Helbig, J. H., Bernander, S., CastellaniPastoris, M., Etienne, J., Gaia, V., Lauwers, S., Lindsay, D., Luck, P. C., Marques, T., Mentula, S., Peeters, M. F., Pelaz, C., Struelens. M., Uldum, S. A., Wewalka, G., and Harrison, T. G (2002). "PanEuropean study on culture-proven Legionnaires' disease. distribution of Legionella pneumophila serogroups and monoclonal subgroups." Eur J ClinMicrobiol Infect Dis 21 (10). 710-716.

[12] Jawetz, E., Melnick, J. L. and Adelberg's, E. A (2013). Medical Microbiology. $26^{\text {th }}$ edition McGraw-Hill Companies press, $U . K$.

[13] Joseph, C. A., Watson, J. M., Harrison, T. G. andBartlett, C. L (1994). Nosocomial Legionnaires' disease in England and Wales, 1980-1992. Epidemiol Infect, 112 (2). 329-345.

[14] Junge - Mathys, E., and Mathys, W (1994). Die Legionellose - ein BeispielfürumweltbedingteInfektionen. [ Legionellosis an example of environmentally caused infections] Intensiv, 2. 29-33.

[15] Kim, B. R., Anderson, J. E., Mueller, S. A., Gaines, W. A., and Kendall, A. M (2002). Literature review -efficacy of various disinfectants against Legionella in wat er systemsWater Res 36 (18). 4433-4444.

[16] Kirby, B. D., Snyder, K. M., Meyer and R. D. Finegold, S (1980). Legionnaires'disease. Report of sixty-five nosocomial acquired cases. Review of the literature." Medicine (Baltimore). 59 (3). 188-205.

[17] Kunz J, Cooley L. (2016) Preventing Legionnaires' disease: Environmental health expertise is key. J Environ Health. 79 (1): 24-6.

[18] Lin, Y. E., Stout, J. E. and Yu, V. L (2011). Prevention of hospital-acquired legionellosis. Curr. Opin. Infect. Dis. 24 (4).
$350-356$.

[19] Miquel, P. H., Haeghebaert, S. Che, D. Campese, C., Cuitard, C., Brigaud, T., Therouanne, M., Panie, S., Jarraud, S. and Dlle, f (2004). Epidemie communautire delegionellose, pasde Calais, France, Novembr 2003- Jnvier 2004. Bull. Epidimiol. Hebd, 37. 179-181.

[20] Murga, R., Forster, T. S., Brown, E., Pruckler, J. M., B. S. Field, B. S., and Donlan, R. M (2001). Role of bio films in the survival of Legionella pneumophilain a modelpotable-water system. Microbiology 147 (11). 3121-3126.

[21] O’Mahony, M. S., Stanwell, R. E., Smith, H. E., Tillentt, D., Harper, J. G., Hutchison, P., Farrell, I. D., Hutchinson, D. N., Lee, J. V., Dennis, P. J., Duggal, H. V., Scully, J. A. and Denne, C (1990). The Stafford outbreak oflegionnaries' disease. Epidimiol. infect. 104 (3). 361-380.

[22] Potts A, Donaghy M, Marley M, et al., (2013) Cluster of Legionnaires disease cases caused by Legionella longbeachae serogroup 1, Scotland, August to September. Euro Surveill 2013; 18: 20656.

[23] Thomas, V., Bouchez, T., Nicolas, V., Robert, S., Loret J. F., and Levi, Y (2004). Amoebae in domestic water systems. resistance to disinfection treatments and implication in Legionella persistence. J. Appl. Microbiol. 97 (5). 950-963.

[24] Watson, J. M., Mitchell, E., Gabbay, J., Maguire, H., Boyle, M., Bruce, J., Tomlinson, M., Lee, J., Harrison, T. G., Uttley, A., O'Mahony, M. and Cunningham, D (1994). Piccadilly Circus Legionnaires' disease outbreak J. Pub. Hlth Med., 16 (3). 341-347.

[25] Yee, R. B. and Wadowsky, R. M (1982). Multiplication of Legionella pneumophilain unsterilized tap water. Applied and Environmental Microbiology, 43 (6). 1330-1334. 